\title{
Yeni Normalin Erken Çocukluk Dönemi Üzerindeki Etkilerinin Ebeveyn Görüşleri Alınarak İncelenmesi
}

\author{
Beyzanur OK', Nurdan TORUN², Dila Nur YAZICI ${ }^{3}$
}

\begin{abstract}
Öz: Bu araştırmanın amacı; pandemi sürecinin erken çocukluk dönemi çocuklarının davranışlarında meydana gelen değişimlerin, aynı zamanda bunların çocuk üzerindeki etkilerinin ebeveyn görüşleri alınarak belirlenmesidir. Etik kurul onayı alınan bu araştırma kapsamında, amaçlı örnekleme yöntemlerinden kartopu örnekleme kullanılarak katılımcılar seçilmiş ve 20 ebeveyn ile görüşülmüştür. Ebeveynlerin fikirleri görüşme tekniği kullanılarak alınmıştır. Temel nitel araştırma yöntemiyle yürütülen çalışma içerik analizi tekniği ile çözümlenmiştir. Araştırmaya katılan ebeveynler, günlük rutinlerinde birtakım değişikliklerin meydana geldiğini ifade etmişlerdir. Bu değişikliklerin sosyal aktiviteler, beslenme saatleri, uyku saatleri, hijyen ve elektronik cihazların kullanımı şeklinde kategorileştiği görülmüş̧ür. Rutinlerde meydana gelen değişimler sonucunda çocuklarda öfke, isyan, mutsuzluk, korku gibi duygusal problemlerin yanında saldırganlık, aşırı hareketlilik ve inatçılık gibi davranışların da ortaya çıktığı sonucuna varılmıştır. Pandemi sürecinde eğitim öğretime ara verilmesiyle çocuklarda okula, öğretmene ve arkadaşlara duyulan özlemin arttığı görülmüştür. Aynı zamanda bu değişimler sonucunda ebeveynlerde endişe, üzüntü, agresiflik gibi durumlar ortaya çıkmıştır.
\end{abstract}

Anahtar Sözcükler: Ebeveyn, Erken çocukluk, Pandemi

\section{The Effects of the Covid-19 Pandemic on Children in Early Childhood Based on Parental Views}

\begin{abstract}
The purpose of this research is the determination of the changes that occur in the behavior of early childhood children of the pandemic process, as well as their effects on child, by taking the views of parents. Within the scope of this study, for which ethics committee approval was obtained, participants were selected using snowball sampling and 20 parents were interviewed. Parents' opinions were taken using the interview technique. The study conducted with the basic qualitative research method was analyzed with the content analysis technique. Parents who participated in the study stated that some changes occurred in their daily routines. It has been observed that these changes are categorized as social activities, feeding hours, sleeping hours, hygiene and use of electronic devices. As a result of the changes in routines, it was concluded that in addition to emotional problems such as anger, rebellion, unhappiness, and fear, behaviors such as aggression, excessive mobility and stubbornness appeared in children. With the interruption of education in the pandemic process, it was observed that the longing for school, teacher and friends increased in children. At the same time, as a result of these changes, situations such as anxiety, sadness, and aggressiveness emerged in parents.
\end{abstract}

Keywords: Parent, Early childhood, Pandemic 
Ekolojik Sistemler Kuramı gelişimi; bireyin çevresini oluşturan ilişkiler sistemi çerçevesinde incelemektedir. Bronfenbrenner (1979), bireyin çevresini oluşturan katmanları tanımlayarak, her bir katmanın erken dönemden itibaren çocuğun gelişimi üzerindeki etkisini açıklamıştır. Bu katmanlar; mikrosistem, mezosistem, ekzosistem ve makrosistemdir. Mikrosistem, bireyin içinde yaşadığı kişinin ailesi, akranları, okulu ve mahallesi gibi bağlamları içeren ortamdır. Bu sistemde çocuk; ebeveyni, akranları, öğretmenleri gibi çeşitli sosyal aktörlerle doğrudan etkileşim kurabilmektedir (Yüksel Doğan ve Aytekin, 2021: 558). Bununla birlikte 2019 yılının son günlerinde Çin'de ortaya çıan virüs, tüm dünya çocuklarının yakın çevresi ve ilişkilerini derinden etkilemiştir.

İyi bilinen bir gerçekliktir ki eğitim kişilerin refah düzeylerinde ve toplumların gelişmesinde benzersiz bir rol oynamaktadır (Gümüş ve Atalmış, 2011). Dünya'ya yayılan Covid-19 salgını sebebiyle başlayan karantina süreci çocukların mikrosistemini de oluşturan eğitim-öğretim olanaklarını sınırlandırmış ve çocukların eğitimlerine online olarak devam etmesi sosyal ve akademik yönden birtakım sonuçları beraberinde getirmiştir. (Çakır Kardeş, 2020). Çocuklar öğrenci rolleriyle yer aldıkları eğitim sisteminde belirli bir oryantasyon sürecine katılamadan uzaktan eğitim faaliyetlerinde yer almak ve bu sürece destekleri olmadan uyum sağlamak zorunda kalmışlardır (Çaykuş ve Mutlu Çaykuş, 2020). Bunun yanında, sınırlı bilgi birikimine ve olgunluk düzeyine sahip olduklarından, çocuklar mevcut pandemik durumun sonuçlarını anlamada sahip oldukları sınırlılıklardan dolayı kendilerini uzaklaştırılmış veya yalnız hissedebilmektedir (Singh vd., 2020). Yaşanan pandemi etkili olduğu ülkelerde insanları bilinmezlik ve karmaşa sürecine itmiş, bu durum çocuklarda kaygıya sebebiyet verebilecek bir olgu olarak belirlenmiştir (Akoğlu ve Karaaslan, 2020). Yetişkinlere göre çocuklar gelişimlerine yön verecek, kendilerinin sosyal ve duygusal, zihinsel ve davranışsal ihtiyaçlarını karşılayacak bağımsız bir güce sahip olmadıklarından ve bunun yanında sınırlı deneyim ve beceri eksikliklerinden dolayı salgın ve doğal afet gibi travma yaratabilecek olaylardan etkilenebilecek kırılgan halkanın ilk sıralarında yer alırlar (Schonfeld ve Demaria, 2015). Bir kriz durumunda nasıl davranacaklarına karar vermek için ebeveynlerine ya da bakıcılarına bağlıdırlar (Phelp ve Sperry, 2020). Bu süreçte erken çocukluk dönemindeki çocuklarda çoğunlukla isteksizlik, oyuna odaklanmada güçlük, biberon kullanımı, parmak emme, tuvalet kazaları gibi kronolojik yaş ve gelişim düzeyiyle uyumu olmayan bazı davranışların yanı sıra, anne-babadan ayrılamama gibi davranış değişikliklerinin gözlenebileceği ifade edilmektedir (Imran, Zeshan ve Pervaiz, 2020). Özellikle ev ortamında çocuğa karşı duygusal etkileşimin yaşanacağı bir iletişim ortamının sunulmamasından dolayı çocukların çevrelerindeki yetişkinlerin duygusal analizini yapmakta ve onlara anlam vermekte yaşadıkları kopukluk kaygı duymalarına açmakta, ortaya çıkan kaygının ise çocukları yalnızlaştırmakta ve içine kapanıp duygularını paylaşmaktan kaçınmalarına sebep olmaktadır (Dalton vd., 2019). Ebeveynlerin çocuklarının salgın süreci içerisinde verdikleri tepkileri büyük bir dikkatle gözlemlemeleri, uyku düzenlerinde gerçekleşen her bir değişikliğin farkında olmaları dolayısıyla çocukların stresini azaltma, onların dikkatlerini daha yaratıcı ve onları olumlu etkileyecek taraflara çekme konusunda rehber ve sürecin getirdiklerini karşılama tarzlarıyla örnek olmalıdırlar (Jiao vd., 2020).

Pandeminin küresel çapta etkilediği sektörlerin başında eğitim gelmektedir. Birleşmiş Milletlerden son edinilen verilere göre dünyada 770 milyon kişilik öğrenen kitle, okul ve üniversitelerin kapanmasından etkilenmiştir (Zhong, 2020). Koronavirüs salgını nedeniyle okulların kapatılması birçok problemi beraberinde getirmiştir. Çocukların günün tamamını ev içerisinde geçirmeleri, akranları ile etkileşimlerinin kopması, rutinlerinde meydana gelen değişimler çocuğun psikososyal, zihinsel, dil, motor gibi tüm gelişim alanlarını etkilemiştir (Haleemunnissa, Didel, Swami, Singh ve Vyas, 2020). Bu süreçte hastalığın yayılmasını önlemek amacıyla yüz yüze eğitime ara verilmiş, bu süreç sadece çocukların eğitimlerini etkilemekle kalmayıp aynı zamanda işsizlik, aile içi geçimsizlik, çalışan ailelerin çocuk bakımında ortaya çıkan sıkıntıları gibi birçok olumsuz sonuçlar getirmiştir (Baxter, Oruç, Keskinocak, Asplund ve Serban, 2020). Epidemiyolojik araştırmalar, çocukların hiperaktivite, davranış sorunları, dışsallaştırma sorunları ve genel psikolojik sıkıntı dahil olmak üzere pandemik felaketlerde özellikle davranışsal zorluklara karşı savunmasız olduklarını belirtmiştir (Clark ve diğerleri, 2020; Dray ve diğerleri, 2017; Wang ve diğerleri, 2020).

İlgili alanyazın incelendiğinde COVID-19 pandemi sürecinde birçok araştırma yapıldığı, bununla birlikte erken çocukluk döneminde yapılan çalışmaların genellikle çocukların psikolojik durumları üzerine olduğu 
görülmektedir (Al-Balushi ve Essa, 2020; Dong ve diğerleri, 2020; Griffith, 2020; Phelps ve Sperry, 2020; Singh ve diğerleri, 2020; Stark ve diğerleri, 2020; Whittle ve diğerleri, 2020). Eğitimle ilgili çalışmalar incelendiğinde ise öğretmenlerin karma grup olarak görüşlerinin incelendiği (Alea ve diğerleri, 2020), K-12 öğrencilerinin görüşlerinin alındığı (Fiş Erümit, 2020) ve lise öğretmen ve öğrencileriyle (Niemi ve Kousa, 2020) çalışmalar yapıldığı belirlenmiştir.

Bununla birlikte bu sürecin çocuk üzerindeki etkilerine ilişkin görüşleri inceleyen bir araştırmaya rastlanılmamıştır. Bu noktadan hareketle, araştırmanın amacını; pandemi sürecinin erken çocukluk dönemi çocuklarının yaşantılarında meydana gelen değişimlerin, aynı zamanda bunların çocuk üzerindeki etkilerinin ebeveyn görüşleri alınarak belirlenmesi oluşturmaktadır. Bu araştırmanın sonuçlarının araştırmacılar ve politika yapıcıların sonraki çalışmalarında yol göstereceği düşünülmektedir. Ebeveynlerin görüşleri doğrultusunda belirlenmeye çalışılan değişimler ve bu değişimlerin çocuk üzerindeki etkisine ilişkin görüşleriyle ileriye yönelik eğitim programları hazırlanabileceği ve önleme çalışmaları gerçekleştirilebileceği düşünülmektedir. Bu amaçla şu sorulara yanıt aranmıştır:

Ebeveynlere göre;

1) Pandemi sürecinin okul öncesi ve okul çağı çocuklarının yaşantılarında meydana getirdiği değişimler nelerdir?

2) Pandemi sürecinin okul öncesi ve okul çağındaki çocukların yaşadığı bu değişimlerin çocuk üzerindeki etkileri nelerdir?

\section{Yöntem}

Pandemi sürecinin erken çocukluk dönemi üzerindeki etkilerinin anne/baba görüşleri alınarak ortaya çıkarılması amacıyla yapılan bu çalışma, nitel araştırma deseninde oluşturulmuştur. Nitel araştırma, araştırmanın temel problemine daha yorumlayıcı yaklaşan ve belirlenen konuya kapsamlı odaklanmayı sağlayan bir araştırma yöntemidir (Tutar ve Tuncay Erdem, 2020). Bu çalışmada nitel araştırma yöntemlerinden temel nitel araştırma deseni kullanılmıştır. Temel nitel araştırmada amaç, bireylerin yaşamı ve tecrübelerini nasıl yorumladığını anlamaktır. Bu yüzden araştırmacılar, kişilerin hayatlarına kattıkları anlam ve yaşadıkları deneyimlerle ilgilenirler (Merriam, 2013). Bilindiği üzere durum çalışmalarında gözlem, görüşme gibi çoklu veri kaynakları kullanılmaktadır. Bununla birlikte yaşanan pandemi sürecinde bu durumun hem ebeveynler hem de araştırmacılar için risk oluşturacağı düşünüldüğü için bu araştırma temel nitel araştırmayla desenlenmiştir.

\section{Çalışma Grubu}

Araştırmanın çalışma grubunu erken çocukluk döneminde (0-8 yaş) çocuğu olan 20 ebeveyn oluşturmaktadır. Bu katılımcıların belirlenmesinde amaçlı örnekleme yöntemlerinden kartopu (zincir) örnekleme kullanılmıştır. Kartopu örneklemede, araştırmacının problemine ilişkin olarak zengin bilgi kaynağı olabilecek birey veya durumların saptanmasında özellikle etkilidir. Süreç, “Bu konuyla ilgili olarak kimle ya da kimlerle görüşmemi önerirsiniz?" sorusuyla başlamaktadır ve elde edilen isimler kartopu gibi büyümektedir (Yıldırım ve Şimşek, 2018). Bu araştırmada kartopu örneklemin seçilmesindeki amaç, 2020-2021 eğitim öğretim yılı güz döneminde verilerin toplandığı tarihte uzaktan eğitim sürecinin olmasıdır. Dolayısıyla okullardan destek alınamamıştır. Bu sebeple ilk ebeveyne ulaştıktan sonra "3-8 yaş aralığında çocuğu olan, okul öncesi eğitim ya da ilkokula devam eden ve araştırmamıza katılmak isteyecek birini önerir misiniz?" sorusu yöneltilmiştir. Katılımcıların yönlendirdiği tüm ebeveynler anne olduğu için çalışma grubunun tamamını anneler oluşturmuştur. Araştırmamıza Katılımcılara ait bilgiler Tablo 1'de verilmektedir.

Tablo 1. Katılımcilara Ait Demografik Bilgiler

\begin{tabular}{ll}
\hline Formu dolduran ebeveynin cinsiyeti & $f$ \\
\hline Anne & 20 \\
\hline Annenin yaşı & $f$ \\
\hline $30-39$ & 17 \\
$40-49$ & 3 \\
\hline Annenin Eğitim Durumu & $f$ \\
\hline
\end{tabular}




\begin{tabular}{|c|c|}
\hline Lise & 3 \\
\hline Önlisans & 4 \\
\hline Lisans & 12 \\
\hline Master/doktora & 1 \\
\hline Annenin Mesleği & $f$ \\
\hline Öğretmen & 11 \\
\hline Ev hanımı & 2 \\
\hline Diğer & 7 \\
\hline Babanın yaşı & $f$ \\
\hline $25-34$ & 3 \\
\hline $35-44$ & 15 \\
\hline $45-54$ & 1 \\
\hline $55-64$ & 1 \\
\hline Babanın Eğitim Durumu & $f$ \\
\hline İlköğretim & 1 \\
\hline Lise & 4 \\
\hline Önlisans & 2 \\
\hline Lisans & 11 \\
\hline Master/doktora & 2 \\
\hline Babanın Mesleği & $f$ \\
\hline Memur & 3 \\
\hline Diğer & 17 \\
\hline \multicolumn{2}{|l|}{ Ailenin aylık geliri } \\
\hline $4000-6000$ & 5 \\
\hline $6001-8000$ & 3 \\
\hline $8001-10000$ & 3 \\
\hline 10001 ve üstü & 9 \\
\hline Ailedeki çocuk sayısı & $f$ \\
\hline 1 & 9 \\
\hline 2 & 11 \\
\hline Araştırmadaki çocuğun cinsiyeti & $f$ \\
\hline$\overline{\mathrm{K}} 1 \mathrm{z}$ & 11 \\
\hline Erkek & 9 \\
\hline \multicolumn{2}{|l|}{ Doğum sırasi } \\
\hline 1 & 16 \\
\hline 2 & 4 \\
\hline Özel gereksinimli olma durumu & $f$ \\
\hline Yok & 20 \\
\hline Çocuğun yaşı & $f$ \\
\hline $4-5$ & 7 \\
\hline $6-7$ & 13 \\
\hline Çocuğun devam ettiği okul & $f$ \\
\hline Özel anaokulu & 9 \\
\hline Devlet anaokulu & 2 \\
\hline Özel ilkokul & 5 \\
\hline Devlet ilkokulu & 4 \\
\hline Çocuğun çevresinde COVID-19 tanı alan kişi & $f$ \\
\hline Var & 6 \\
\hline Yok & 14 \\
\hline
\end{tabular}

Yukarıda da bahsedildiği gibi araştırmaya katılan ebeveynlerin tamamı annelerden oluşmaktadır. Bu annelerden on yedisinin yaş aralığının 30-39, üçünün ise 40-49 olduğu tespit edilmiştir. Çocukların yedisinin yaş aralığının 4-5, on üçünün yaş aralığının 6-7 olduğu ve çocukların çoğunluğunun özel anaokulunda eğitim gördükleri saptanmıştır. Görüşmeler esnasında 14 çocuğun yakınlarında COVID-19 tanısı almış biri yokken, altı çocuğun yakınında tanı almış birisi olduğu belirlenmiştir.

\section{Veri Toplama Araçları}

Araştırmada veri toplama araçları olarak demografik bilgi formu ve yarı yapılandırılmış görüşme soruları kullanılmıştır. Aşağıda veri toplama araçlarıyla ilgili bilgi verilmektedir.

\section{Demografik Bilgi Formu}


$\mathrm{Bu}$ formda ebeveynlerin yaşı, mesleği, eğitim durumu, aylık geliri, çocuğu yaşı, cinsiyeti, doğum sırası, özel gereksiniminin olup olmadığı, çocuğun hangi eğitim kademesinde olduğuyla ilgili sorular yer almaktadır.

\section{Yarı Yapılandırılmış Görüş̧me Soruları}

Yarı yapılandırılmış görüşme soruları oluşturulurken araştırmacılar tarafından araştırmanın görüşme sorularına paralel olarak sorular hazırlanmıştır. Ardından hazırlanan görüşme soruları üç alan uzmanına gönderilmiş ve bir alan uzmanının önerileri doğrultusunda akademik becerilerle ilgili ayrı bir soru hazırlanmış, bulgularda ise birleştirilerek sunulmuştur.

\section{Veri Toplama Süreci}

Veri toplama süreci telefon görüşmeleri aracılığıyla gerçekleştirilmiştir. Görüşmelere başlamadan önce ebeveynlerden ses kaydı için izin alınmıştır. Görüşme sorularına geçilmeden önce katılımcılar araştırmanın içeriği ve etik hususlar konusunda bilgilendirilmiştir. Görüşmeler bu makalenin birinci ve ikinci yazarları tarafından gerçekleştirilmiştir. Görüşmeler ebeveynler ve araştırmacılar için uygun olan bir zaman diliminde gerçekleştirilmiştir. Görüşmeler 21 dakika ile 37 dakika arasında sürmüştür.

\section{Verilerin Analizi}

Verilerin analizinde içerik analizi kullanılmıştır. İçerik analizinde amaç; “toplanan verileri açıklayabilecek kavramlara ve ilişkilere ulaşmak"tır (Yıldırım ve Şimşek, 2018, ss. 227). Bu araştırmada verilerin analiz edilmesinde şu yol takip edilmiştir: 1) Veri toplama süreci tamamlandıktan sonra her bir görüşmeye ait ses kayıtları E.1, E.2... gibi isimler verilerek bilgisayarda bir dosyaya yüklenmiştir. Ardından ses kayıtları, herhangi bir değişiklik yapılmadan araştırmanın ikinci ve üçüncü yazarları tarafından görüşme formlarına aktarılmıştır. Tüm görüşmeler yazılı hale getirildikten sonra yansız atama yoluyla belirlenen beş ebeveynin verileri (görüşmelerin \%25'i) araştırmada transkript yapmayan araştırmacı tarafından doğrulanmıştır. 2) Transkript işlemi tamamlandıktan sonra araştırmacılar birbirinden bağımsız olarak verileri kodlamışlar ve temalara ayırmışlardır. Ardından araştırmacılar bir araya gelerek kodlarını ve temalarını incelemişlerdir. Miles ve Huberman'ın (1994) formülüne göre (görüş birliği/ görüş birliği+görüş ayrıllı̆̆) güvenirlik ilk olarak \%86 çıkmıştır. Ardından araştırmacılar görüş ayrılığı olan konularda konuşarak görüş birliğine varmışlardır. Görüş birliğine varıldıktan sonra kodlar ve temalar düzenlenerek bulgular tanımlanmış ve yorumlanmıştır. Son olarak araştırmaya katılan ebeveynlerden ikisine (\%10) bulgular okutularak bulguların düşüncelerini yansıtıp yansıtmadığını belirtmeleri istenmiştir. Katılımcılar bulguların düşüncelerini bütünüyle yansıttıklarını belirtmişlerdir.

\section{Araştırmanın Geçerliği ve Güvenirliği}

Araştırmanın Dış Geçerliği: Nitel araştırmalarda amaç elde edilen sonuçları başka ortam ve durumlara genellemek değil; onun yerine elde edilen sonuçları benzer ortamlara aktarabilmektir (Shenton, 2004; Yıldırım ve Şimşek, 2013). Bu araştırmada dış geçerliği sağlamak amacıyla ayrıntılı betimleme ve amaçlı örnekleme tercih edilmiştir.

Araştırmanın İç Geçerliği: Bu araştırmada iç geçerliği sağlamak amacıyla uzman incelemesi ve katılımcı teyidi kullanılmıştır.

Araştırmanın Güvenirliği: Nitel araştırmalarda güvenirlik araştırmacının ulaştığı sonuçları topladığı verilerle teyid etmesini gerekli kılmaktadır (Yıldırım ve Şimşek, 2013). Bu araştırmada kullanılan dış güvenirlik metodu kısa teyiddir. 


\section{Bulgular}

\section{Ebeveynlerin Pandemi Sürecinde Çocuklarında Meydana Gelen Değişikliklere İlişkin Görüşleri}

Ebeveynlere, pandemi sürecinde çocuklarında gördükleri değişimlerin neler olduğunu sormadan önce pandemi sürecinde çocuklarının hayatlarında nasıl değişimler olduğu sorulmuştur. Bu değişimlerin neler olduğu Şekil 1'de sunulmaktadır.

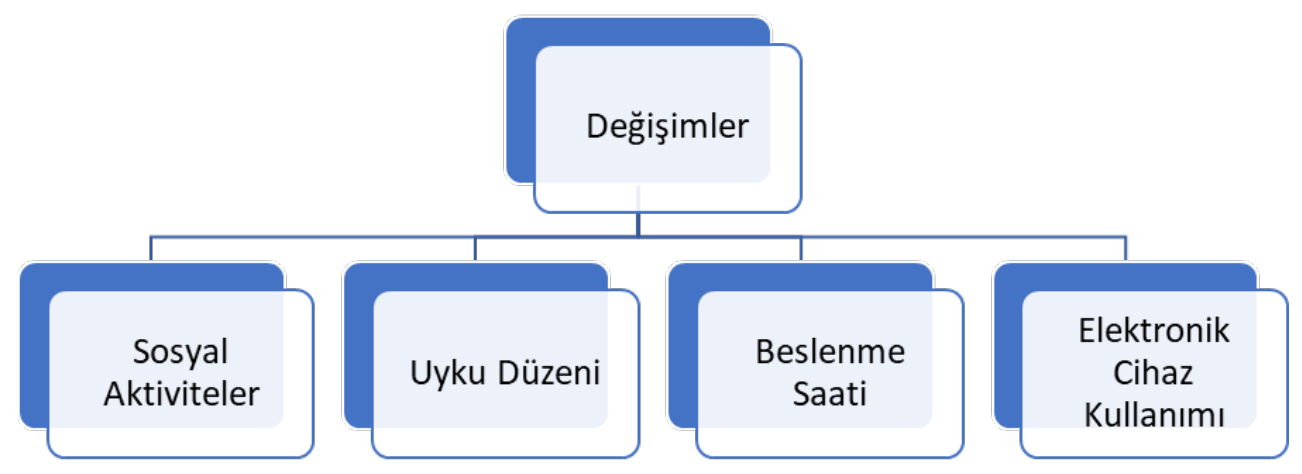

Şekil 1. Ebeveynlere Göre Pandemi Sürecinde Çocuklarının Yaşantılarında Meydana Gelen Değişimler

Şekil 1 incelendiğinde ebeveynler pandemi süreci dolayısıyla sosyal aktivitelerinde, uyku düzenlerinde, beslenme saatlerinde ve elektronik cihaz kuıllanımlarında değişimler olduğunu belirtmiştir. Aşağıda bu değişimler detaylı bir şekilde anlatılmaktadır.

\section{Sosyal Aktiviteler}

Bu konuyla ilgili olarak ebeveynlerin birçoğu bu konuyla ilgili olarak mekan kısıtlamalarından söz etmiştir. Ayrıca aile olarak yaptıkları etkinliklerin ksıtlanmasından söz etmişlerdir. Bu konuyla ilgili olarak E.9 ve ve E.15 şunları ifade etmiştir:

Çok değişiklikler oldu. Gezmeye gidemedik, evde kaldık. Biz ailecek gezmeyi çok sevdiğimiz için, hafta sonu muhakkak bir günümüz gezme ile geçerdi. Dağa giderdik, yeşillik alanlara giderdik, çocuk rahat hareket edebilsin koşabilsin diye. Ama şu an tamamen eve tıkılıp kaldık (E. 9)

Önceden dışarı çıktığımızda park, bahçe, avm, sinema gibi yerlere gidiyorduk. Bunların hiçbirini yapamıyoruz (E. 15)

\section{Uyku Düzeni}

Bu konuyla ilgili olarak ebeveynlerin bir kısmı çocuklarının geç yatmaya başladıklarını belirtmiştir. Bazı ebeveynler ise uyku düzensizliğinden ve çocuklarının uyku kalitesinin düştüğünden söz etmiştir. Bir ebeveyn ise çocuğunun uyku düzeninin iyileştiğini belirtmiştir. Bu konuyla ilgili olarak E.2 ve E.8 şunları ifade etmiş̧tir:

Uyku düzeninde değişiklikler oldu. Şu an evde olduğumuz için, okul döneminde okullar erken açıldığı için erken yatıyorlardı. Ama şimdi şu süreçte biraz daha uzadı. Hani bir iki saat daha geç yatıyorlar (E. 2)

Özellikle okullar kapandığı dönemde geç saatlerde yatıp geç saatlerde kalktı (E. 8)

\section{Beslenme Saati}

$\mathrm{Bu}$ konuyla ilgili olarak ebeveynlerin bir kısmı çocuklarının aşırı yediklerini, abur cubura düşkünlüklerinin arttıklarını belirtmiştir. Bazı ebeveynler ise öğünlerin aksadığını belirtmiştir. Bu konuyla ilgili olarak E.7, E.10 ve E.14 şunları ifade etmiştir: 
Yeme içme alışkanlıkları değişti. Yemek yemeye verdi kendini mesela. Sürekli dolapları kurcalıyor. Ben saklasam dahi sandalyeye çıkıyor. Dolabın içinde ne var diye yiyecek bir şeyler arıyor. Özellikle yemek konusunda çok etkilendi (E. 7)

Ara öğünlere abur cuburlar yerleşmeye başladı. Ama onda da yapabileceğim bir şey yok. Çocuklara bu süreçte hak vermek lazım (E. 10).

Tabii, biraz daha geç yiyoruz, akşamları erken yiyoruz (E. 14).

\section{Elektronik Cihaz Kullanımı}

$\mathrm{Bu}$ konuyla ilgili olarak ebeveynlerin neredeyse tamamı bu cihazların kullanımıyla ilgili bir artış olduğunu belirtmiştir. Bu konuyla ilgili olarak bazı katılımcılar şunları ifade etmiştir:

Sadece bu süreçte bilgisayar ve tabletle daha çok haşır neşir. Canlı dersleriyle birlikte bu durum ortaya çıtı ve dersten sonra kendisi de oynamak istiyor bu beni çok rahatsız ediyor (E. 5)".

Televizyona aşırı derecede bağlandılar. Oradaki şeyleri anlatıyorlardı. Onları izleyip ordaki olayları alıyorlardı, sanki gerçek dünyaymış gibi. Onları anlatmaya çalışıyorlardı. Hani günlük konuşmalarımızda televizyonlardaki, çizgi filmlerdeki şeyleri konuşuyorduk diyebilirim (E. 13).

Bilgisayar, televizyon ve tablet bağımlılığı çok ciddi anlamda arttı (E.18)

\section{Ebeveynlere Göre Pandemide Gerçekleşen Değişimlerin Çocukları Üzerindeki Etkileri}

Araştırmaya katılan ebeveynlerin pandemi sürecindeki değişimlerin çocukları üzerindeki etkilerine ilişkin görüşleri Şekil 2'de sunulmaktadır.

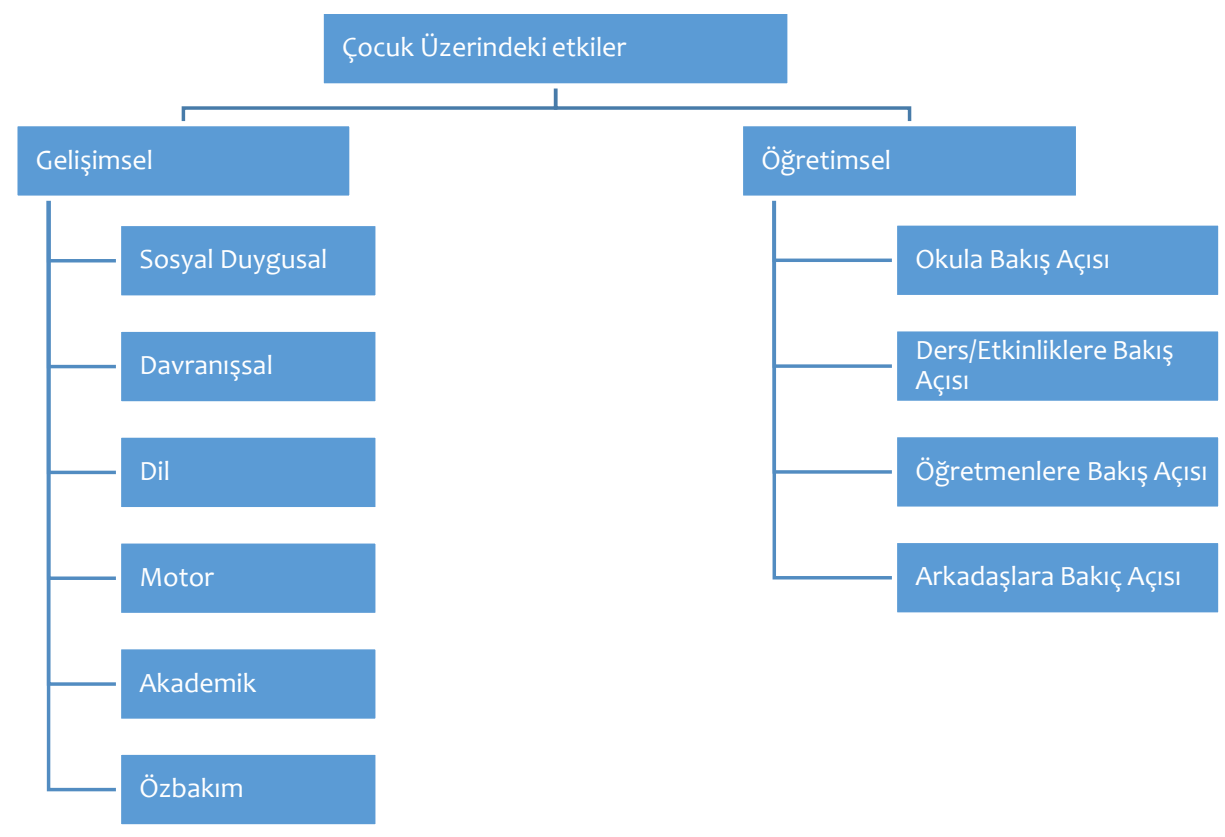

Şekil 2. Pandemi Sürecinin Çocuklar Üzerindeki Etkilerine İlişkin Ebeveyn Görüşleri

Şekil 2 incelendiğinde pandemi sürecinin çocukta yarattığı değişikliklerin etkileri ebeveynlere göre iki ana kategoride toplanmaktadır: Gelişimsel ve öğretimsel. Gelişimsel boyut incelendiğinde ebeveynlerin sosyal duygusal, davranışsal, dil, motor, akademik ve özbakım alanlarında etkileri olduğunu düşündükleri belirlenmiştir. Öğretimsel boyut incelendiğinde ise ebeveynlerin okula bakış açısı, ders/etkinliklere bakış açısı, öğretmene bakış açısı ve arkadaşlarına bakış açısı alanlarında etkileri olduğunu düşündükleri belirlenmiştir. Aşağıda bu boyutlar detaylı bir şekilde açıklanmaktadır:

\section{Gelişimsel Etkiler}

Ebeveynler pandemi sürecinde çocuklarının yaşadığı değişimlerin gelişimsel olarak sosyal duygusal, davranışsal, dil, motor, akademik ve özbakım alanlarında etkileri olduğunu düşündükleri belirlenmiştir. Aşağıda bu konuyla ilgili ayrıntılı betimlemeler yer almaktadır.

Sosyal Duygusal: Katılımcıların birçoğu pandemi süreci dolayısıyla çocuklarında öfke, isyan, mutsuzluk, 
içe kapanma, üzüntü, korku, gerginlik, kaybetme korkusu, özlem, yalnız hissetme, kaygı gibi durumlar oluştuğunu belirtmiştir. Bu konuyla ilgili olarak E.1., E.7, E.12 ve E.18 şunları ifade etmiştir:

Evet arkadaşlarını görememek onu üzdü. Hatta geçen seneki doğum gününü yapamamak onu çok üzdü (E.1)

Bitsin şu covid bıktım artık, öf ölsün de kurtulalım, ne yapmamız lazım? ” diyor (E.7)

'Daha sinirli bir çocuk olmaya başladı, daha hırçın... (E.12)

"Anne çok mutsuzum. Ne zaman açlacak okul? Arkadaşlarımı ne zaman görebileceğim? (E.18)

Davranışsal Etkiler: Araştırmaya katılan ebeveynlerin birçoğu çocuklarında davranışsal etkilerin olduğunu belirtmiştir. Verilen cevaplar incelendiğinde ebeveynler çocuklarının saldırganlık, aşırı hareketlilik, inat, şımarıklık, ağlama, parmak gibi olumsuz davranışsal değişiklikler yaşadıklarını belirtmiştir. Bununla birlikte bir ebeveyn bu dönemde çocuğunun daha yaratıcı olduğunu belirtmiştir. Bu konuyla ilgili olarak E.3, E.11 ve E.17 şunları ifade etmiştir:

Can sıkıntısı yaşıyor evde. ...Sürekli koltuk tepelerinde, zıplıyor, atlıyor... (E.3)

Öfke kontrolsüzlüğü var. Ters hareketler, davranışlar var. (E.11)

Bu süreçte bana göre daha yaratıcı oldu, daha farklı çizimler yapıyor. (E.17)

Dil Gelişimi: Ebeveynler bu süreçte çocuklarının bağırmaya başladıklarını, konuşmada güçlük yaşadıklarını, aile içi iletişim konusunda sıkıntılar yaşadıklarını, çocuklarının kaba ifadeler kullandıklarını, çı̆̆lık atmaya başladıklarını ve iletişim kurmayı reddettikleri belirlenmiştir. Bu konuyla ilgili olarak E.2 ve E.3 şunları ifade etmiştir.

Önceden daha sakindi, şimdi bağırarak ifade ediyor kendini (E. 2)

Hemen bağırarak, sesini çıkarabildiği kadar çıkarıyor ki, o şekilde bastırmaya çalışıyor (E. 3)

Motor Beceriler: Bu konuyla ilgili olarak ebeveynlerin bir kısmı görüş bildirmiştir. Ebeveynler bu dönemde çocuklarının resim yapmayı ve makas kullanımını bıraktıklarını, kalem tutuşlarının iyi olmadığını belirtmiştir. Bu konuyla ilgili olarak E.14 şunları ifade etmiştir.

Benim kızım çok güzel resim yapardı, boyama yapardı. Bu şeyde pandemi sürecinden itibaren 6 ay kalemi doğru düzgün eline almadı, "elim titriyor" dedi (E.14)

Akademik Beceriler: Bu konuyla ilgili olarak ebeveynler çocuklarında derse/etkinliklere katılımda ilgisizlik olduğunu, ders/etkinlik takibinde isteksizlik olduğunu, akademik becerilerin ediniminde gerilik olduğunu, dikkat dağınıklığını ve ders/etkinlik için kaygılarının olduğunu belirtmişlerdir. Bu konuyla ilgili olarak E.8 ve E.20 şunları ifade etmiştir.

Etkinlik yapmak istemiyor. (E.8)

Birinci sınıfta ve derslere karşı hiç ilgisi yok! (E.20)

Özbakım Becerileri: Bu konuyla ilgili olarak bazı ebeveynler tuvalet ve giyim becerileri üzerine odaklanmıştır. Bu konuyla ilgili olarak E.15 şunları ifade etmiştir:

Hepsi de değişti. Şu an hiçbirini kendi yapmıyor. Okulda yemeğini kendi yerdi. Kıyafetlerini giyerdi, ayakkabısını değiştirirdi. Şu an her şeyi bize yaptırıyor (E.15)

\section{Öğretimsel Etkiler}

Ebeveynler pandemi sürecinde çocuklarının yaşadığı değişimlerin öğretimsel olarak okula bakış açısı, ders/etkinliklere bakış açısı, öğretmene bakış açısı ve arkadaşlarına bakış açısı konularında etkileri olduğunu düşündükleri belirlenmiştir. Aşağıda bu konuyla ilgili ayrıntılı betimlemeler yer almaktadır.

Okula Bakış Açısı: Bu konuyla ilgili olarak ebeveynlerin bir kısmı çocuklarında okula özlem oluştuğunu, bir kısmı okula karşı isteksizlik oluştuğunu belirtmiştir. Bu konuyla ilgili E.1 ve E.8 şunları ifade etmiştir.

Okullar yıkılsın isteyen bir çocuktu, yaz tatilinde köyde vakit geçirdiği için. Ama şu an da okulu özledi ve okulu istemeye başladı (E. 1) 
Az önce de söyledim, geç yatıp geç kalkmaya başladı, bu yüzden de derslere girme konusunda bir isteksizlik hali oldu. (E.8)

Ders/Etkinliklere Karşı Bakış Açısı: Bu konuyla ilgili olarak ebeveynlerin bir kısmı çocuklarında isteksizlik olduğunu belirtmiştir. Ayrıca bir ebeveyn çocuğunda başarısızlık hissinin oluştuğundan bahsetmiştir. Bu konuyla ilgili olarak bir ebeveyn şunları ifade etmiştir.

Evden derse girmek istemiyor. Öğretmenimi seviyorum ama okulda seviyorum bilgisayardan değil (E. 4)

Öğretmenlerine-Arkadaşlarına Bakış Açısı: Ebeveynlerin birçoğu çocuklarının arkadaşlarını özlediğini dile getirmiştir. Ayrıca bir kısmı çocuklarının öğretmenlerini özlediğini dile getirirken, bir kısmı çocuklarının öğretmenleriyle bağ kuramadıklarını belirtmiştir. Bu konuyla ilgili olarak bir ebeveyn şunları ifade etmiştir:

Öğretmenimi ve arkadaşlarımı özledim diyordu. "Keşke okullar açılsa da arkadaşlarımı öğretmenlerimi görsem, okulu özledim" dedi (E.8)

\section{Sonuç ve Tartışma}

Pandemi sürecinin gündelik hayatı psikolojik, fizyolojik ve sosyal alan gibi pek çok açıdan olumlu ve olumsuz etkilediği görülmektedir. Özellikle çocukların bu süreç içerisinde nasıl etkilendiklerine dair fikir sahibi olunması, gerekli müdahalelerin yapılması açısından önem arz etmektedir. Bu sebeple bu araştırmanın amacını pandeminin erken çocukluk dönemindeki çocukların yaşantıları üzerinde nasıl değişimler yarattı̆̆ı ve bu değişimlerin çocuklar üzerindeki etkilerinin neler olduğunun belirlenmesi oluşturmuştur.

Yapılan görüşmeler sonucunda ebeveynlerin çocuklarının yaşamlarındaki değişiklikleri sosyal aktiviteler, uyku düzeni, beslenme saatleri ve elektronik cihaz kullanımı olarak belirtmiştir. Ebeveynler bu dönemde mekân kısıtlamaları ve ailece yapılan etkinliklerin değişim gösterdiğini belirtmiştir. Bunun yanında uyku düzeninde çocukların daha geç yattığı rapor edilirken kimi ailelerde uyku düzeninin değişmediği sonucuna ulaşılmıştır. Bunun yanında uyku kalitesinde düşüş ve uyku düzensizliği de aileleri tarafından çocuklarda gözlenmiştir. Beslenme saatlerinde ise çoğunluk rutinlerinin dışına çıkmadıklarını ancak evde olma halinden dolayı aşırı beslenme, öğün aksaması ve abur cuburla beslenmenin ailelerde en çok görülen beslenme değişimi olarak kaydedilmiştir. Aileler yeni normalin bir getirisi olarak maske kullanımını da günlük rutinlerindeki bir değişim olarak algılamış, bunun yanında çocukların evde olmalarından dolayı elektronik cihaz kullanımında çoğunluğu artış olduğunu ifade etmiştir. Çalışmanın bulgularını destekler nitelikte Brazendale ve diğerleri (2017) çocukların okula gitmediği hafta sonları ve yaz tatilleri gibi zamanlarda fiziksel aktif durumlarının daha düşük olduğunu, ekran karşısında daha çok vakit geçirdiklerini, uyku düzensizlikleri yaşadıklarını ve daha az uygun diyetlere sahip olduklarını ve bunun da kilo alımına ve kalp-solunum zindeliğinin kaybına neden olduğunu ifade etmişlerdir. Okullar, yalnızca çocuklara eğitim materyalleri sağlamada değil, aynı zamanda çocuklara öğretmenlerle etkileşimde bulunma ve psikolojik danışma alma fırsatı sunmada da kritik bir role sahiptir (Wang ve diğerleri, 2020). Dolayısıyla okul ortamları, obezite riskinde rol oynayan üç baskın yaşam tarzı faktörü olan yemek zamanları, fiziksel aktivite ve uyku programı etrafında yapı ve rutin sağlamaktadır (Pietrobelli ve diğerleri, 2020). Bunun yanında Yıldız ve Bektaş (2021) teknolojik araçların ebeveynlerin çocuklarını denetim altına almasını kolaylaştırdığı sonucuna ulaşmıştır. Dolayısıyla ebeveynlerde rastlanan 'denetim altına alma' davranışının çocukların elektronik cihazlarla vakit geçirme süresini uzattığı düşünülmektedir.

Ebeveynler, çocukların rutinlerinde meydana gelen değişimlerin çocukların sosyal-duygusal, davranışsal, dil gelişimi ve motor becerileri üzerinde bir takım etkiye sebep olduğunu belirtmiştir. Çocuklarda en çok rastlanan duygu değişiminin öfke olduğu, isyan, mutsuzluk, içine kapanma, üzüntü, kaybetme korkusu; davranışlarında saldırganlık ve aşııı hareketlilik, inat, ağlama ve parmak emme; dil gelişimlerinden konuşma becerileri ele alındığında kendilerini bağırarak ifade etmenin ortaya çıktığı, konuşmada güçlük yaşandığı, çocuğun iletişim kurarken kaba ifadeler kullandığı; motor becerilerinde bir gerilemenin gözlemlenmediği bunun yanında çocuklarda etkinliğe/derse ilgisizliğin arttığı ağırlıklı olarak bahsedilmiştir. Özellikle okul öncesi çağı çocuklarının ebeveynleri, öz bakım becerilerinde çocuklarının gerileme yaşadığını, tuvalet becerisi ve giyinme ve diğer becerileri kendilerinin yapmamayı tercih ettiğini belirtmişlerdir. Süreç içerisinde gözlemlenen saldırganlık, depresyon, panik ve paranoya gibi 
normal olmayan davranışlar salgının insanları yalnızca fiziksel olarak etkilemediğini ancak psikososyal ve duygusal açıdan da birtakım etkileri olduğu göstermiştir (Karakaş, 2020). Bununla beraber enerjilerini bir şekilde oyun oynayarak, fiziksel aktivitelere katılarak atamayan çocukların fizyolojik, psikolojik ve sosyal olarak olumsuz etkilendiği bunun yanında yeterince fiziksel aktivitelerde bulunmayan çocuklarda depresyon ve yüksek kaygı gibi istenmedik davranışların görülebildiği ifade edilmektedir (Yıldız ve Bektaş, 2021). Dolayısıyla çocuklarda görülen saldırganlık, inat ve ağlama gibi olumsuz davranışların sebepleri arasında enerjilerini atamamaları, mekân kısıtlaması yaşamaları sayılabilir. Imran, Zeshan ve Pervaiz (2020) okul çağına gelmiş çocuklarda araştırmanın bulgularını destekleyen korku ve kaygıda belirgin artı̧, kardeşlerle sorun yaşama, huzursuzluk, saldırganlık, psikolojik kökenli fiziksel hastalık şikayetleri, sorumluluklardan kaçış ve/veya sorumluluklarını yerine getiremeyecek düzeye gerileme (öz bakım becerilerinden tuvalet becerileri, giyinme ve diğer) davranışlarının gözlemlendiği belirtilmiştir.

Çocuğun okula bakış açısında meydana gelen değişimlerde ise okula özlem, okula karşı isteksizlik; ders/etkinliklere karşı isteksizlik, başarısızlık kaygısı; online eğitimden dolayı öğretmenle bağ kuramama ve/veya öğretmenine özlem ve arkadaşlarına özlem duydukları şeklinde veri elde edilmiştir. Arkadaşlık, çocukların normal psikolojik gelişimi ve iyiliği için gereklidir (WHO, 2004) ve çocukların evde kalması ve okul ortamından uzaklaşmasının, arkadaşlarından ve öğretmenlerinden uzak olma ruhsal ve fiziksel sağlığa olumsuz etkileri bulunmaktadır (Brooks ve diğerleri, 2020). Pandeminin insanları evde kalmaya ve çalışmaya mecbur etmesi ebeveynlerin iş ve ev hayatındaki sınır ve düzenin tamamen ve/veya kısmen ortadan kalkmasına sebep olmuştur. Bununla birlikte çocukların da yüz yüze eğitimden uzaktan eğitime geçiş yapmaları ev içerisinde birtakım değişikliklerin yapılmasını gerekli kılmıştır. Bu durum doğal olarak hem ebeveyn hem de çocuk açısından dengeyi korumayı güçleştirmekte, çocukların yetişkinlere nazaran daha kırılgan hissetmelerine sebep olmaktadır. Bu da çocuklarda belirsizlik hakkında daha fazla bilgi ve kesinlik ihtiyacı duymalarına sebep olmaktadır (Akoğlu ve Karaaslan, 2020).

Araştırma sonucunda aşağıdaki öneriler getirilebilir:

Görüşmelerin hepsi annelerle yapıldığından, katılımcı annelerin süreç içerisinde hem ev hem iş hem çocuk ve kendi ihtiyaçları arasında yetersizlik duygusuna kapıldığı ve annede meydana gelen ufak bir duygusal olumsuzluğun çocuğa yansıdığı görüşmelerde fark edilmiştir. Bu yüzden yeni normal süreci içerisinde ailelere destek paketlerinin oluşturulması, özellikle çok iş altında kalıp yetersizlik hissine kapılan annelere psikolojik destek sağlanması gerekmektedir.

Sürecin belirsizliği ebeveynlere ve çocuklara korku, endişe, çaresizlik hissi olarak geri döndüğü görüşmeler sonucunda elde edilen veriler arasındadır. Dolayısıyla ebeveyn ve çocuk odaklı ve toplumun her kesimini kapsayacak şekilde belirsizliklerle yüzleşme, sürece adapte olma desteği, sürecin gerektirdiği şekilde çevrimiçi platformlardan ve istek ve ihtiyaca dayalı sosyal mesafenin korunduğu merkezlerde sağlanmalıdır.

Duyuşsal ve bilişsel olumsuz etkilerini en aza indirmek ve psikolojik iyi oluşu desteklemek adına toplumun ve özellikle çocukluk travması olmaması adına geleceğin yetişkinleri olacak olan çocukların, bu süreci daha sağlıklı atlatmaları adına, ailelerin çevrelerinde bulunan doğal park, piknik alanları vb. doğa içi aktivitelere teşvik edilmesi önerilmektedir.

\section{Yazar(lar)ın Beyanı}

Araştırmacıların katkı oranı beyanı: Araştırmacılar çalışmaya eşit oranda katkı yapmışlardır.

Etik Kurul Kararı: Araştırma için Ondokuz Mayıs Üniversitesi Sosyal ve Beşer̂̂ Bilimler Etik Kurulu'ndan 28.02.2020 tarihinde etik izin alınmıştır.

Çatışma beyanı: Araştırmada yazarlar arasında ya da diğer kişi/kurum/kuruluşlarla herhangi bir çıkar çatışması yoktur.

Destek ve teşekkür: Bu araştırma için herhangi bir kurumdan finansal destek alınmamıştır. 


\section{Kaynaklar}

Akoğlu, G. \& Karaaslan, B.T. (2020). Covid-19 ve izolasyon sürecinin çocuklar üzerindeki olası psikososyal etkileri. İzmir Katip Çelebi Üniversitesi Sağllk Bilimleri Fakültesi Dergisi, 5(2), 99-103.

Al-Balushi, B., \& Essa, M. M. (2020). The impact of COVID-19 on children- parent's perspective. International Journal of Nutrition, Pharmacology, Neurological Diseases, 10(3), 164-165.

Alea, L. A., Fabrea, M. F., Roldan, R. D. A., \& Farooqi, A. Z. (2020). Teachers' Covid-19 awareness, distance learning education experiences and perceptions towards institutional readiness and challenges. International Journal of Learning, Teaching and Educational Research, 19(6), 127-144.

Baxter, A., Oruc, B., Kesinocak, P., Asplund, J. \& Serban, N. (2020). Evaluating scenarious for school reopening under COVID-19. Research Square, 1-14.

Brazendale, K., Beets, M. W., Weaver, R. G., Pate, R. R., Turner-McGrievy, G. M., Kaczynski, A. T. \& von Hippel, P. T. (2017). Understanding differences between summer vs. school obesogenic behaviors of children: the structured days hypothesis. International Journal of Behavioral Nutrition and Physical Activity, 14(1), 1-14.

Bronfenbrenner, U. (1979). The ecology of human development. London: Harvard University Press

Brooks, S. K., Webster, R. K., Smith, L. E., Woodland, L., Wessely, S., Greenberg, N. \& Rubin, G. J. (2020). The psychological impact of quarantine and how to reduce it: rapid review of the evidence. The Lancet, 395(10227), 912-920.

Clark, H., Coll-Seck, A.M., Banerjee, A., Peterson, S., Dalglish,... \& Costello, A. (2020). A future for the world's children? A WHO-UNICEF-Lancet Commission. The Lancet, 395(10224), 605-658.

Çakır Kardeş, V. (2020). Pandemi süreci ve sonrası ruhsal ve davranışsal değerlendirme. Türkiye Diyabet ve Obezite Dergisi, 2, 160-169.

Çaykuş, E.T. \& Mutlu Çaykuş, T. (2020). Covid-19 pandemi sürecinde çocukların psikolojik dayanıklılığını güçlendirme yolları: Ailelere, öğretmenlere ve ruh sağllğı uzmanlarına öneriler. Avrasya Sosyal ve Ekonomi Araştırmaları Dergisi, 7(5), 95-113.

Dalton, L., Rapa, E., Ziebland, S., Rochat, T., Kelly, B., Hanington, L., Bland, R., Yousafzai, A. \& Stein, A. (2019). Communication with children and adolescents about the diagnosis of a life- threatening condition in their parent. The Lancet, 393(10176), 1164-1176.

Doğan, R. Y. \& Aytekin, Ç. (2021). Ekolojik Sistem Kuramı çerçevesinden ebeveyn yabancılaşmasına genel bir bakış. Psikiyatride Güncel Yaklaşımlar, 13(3), 551-572.

Dong, M., Mo, X., Hu, Y., Qi, X., Jiang, F., Jiang, Z. \& Tong, S. (2020). Epidemiology of COVID-19 among children in China. Pediatrics, 145(6), 1-10.

Dray, J., Bowman, J., Campbell, E., Freund, M., Wolfenden, L., Hodder, R.K., McElwaine, K., Tremain, D., Bartlem, K., Bailey, J., Small, T., Palazzi, K., Oldmeadow, C. \& Wiggers, J. (2017). Systematic review of universal resilience-focused interventions targeting child and adolescent mental health in the school setting. Journal of the American Academy of Child \& Adolescent Psychiatry, 56, 813-824.

Fiş Erümit, S. (2021). The distance education process in K-12 schools during the pandemic period: evaluation of implementations in Turkey from the students perspective. Technology, Pedagogy and Education, 3(1), 7594.

Griffith, A. K. (2020). Parental burnout and child maltreatment during the COVID-19 pandemic. Journal of Family Violence. https://doi.org/10.1007/s10896-020-00172-2

Gümüş, S. \& Atalmış, E.H. (2011). Exploring the relationship between purpose of computer usage and reading skills of Turkish students: Evidence from PISA 2006. TOJET: The Turkish Online Journal of Educational 
Technology, 10(3), 129-140.

Haleemunnissa, S., Didel, S., Swami, M., Singh , K. \& Vyas, V. (2020). Children and COVID19: Understanding impact on the growth trajectory of an evolving generation. Children and Youth Services Review, 120, 105754.

Imran, N., Zeshan, M. ve Pervaiz, Z. (2020). Mental health considerations for children and adolescents in COVID-19 Pandemic. Pakistan Journal of Medical Sciences, 36 (COVID19-S4).

Jiao, W. Y., Wang, L. N., Liu, J., Fang, S. F., Jiao, F. Y., Pettoello-Mantovani, M. \& Somekh, E. (2020). Behavioral and emotional disorders in children during the COVID-19 epidemic. The Journal of Pediatrics, 221, 264-266.

Karakaş, M. (2020). Covid-19 Salgınının çok boyutlu sosyolojisi ve yeni normal meselesi. İstanbul Üniversitesi Sosyoloji Dergisi, 40(1), 541-573.

Merriam, S. B. (2013). Nitel araştırma. Desen ve uygulama için bir rehber. (Çev. Ed. S. Turan). Ankara: Nobel Akademik Yayıncılık.

Miles, M. B., \& Huberman, A. M. (1994). Qualitative data analysis: An expanded source book. Thousand Oaks, CA: Sage.

Niemi, H. M. \& Kousa, P. (2020). A case study of student's and teacher's perceptions in a Finnish high school during the COVID pandemic. International Journal of Technology in Education and Science, 4(4), 352-369.

Phelps, C. \& Sperry, L.L. (2020). Children and the covid-19 pandemic. American Psycological Association, 12 (1), 73-75.

Pietrobelli, A., Pecoraro, L., Ferruzzi,A., Heo, M., Faith, M., Zoller, T., Antoniazzi, F., Piacentini, G., Fearnbach, N. S. \& Heymsfield, S. B. (2020). Effects of COVID-19 lockdown on lifestyle behaviors in children with obesity living in Verona, Italy: A longitudinal study. Obesity, 28(8), 11382-1385.

Schonfeld, D. J. \& Demaria, T. (2015). Providing psychosocial support to children and families in the aftermath of disasters and crises. Pediatrics, 136(4), 1120-1130.

Shenton, A. K. (2004). Strategies for ensuring trustworshiness in qualitative research projects. Education for Information, 22(2004), 63-75.

Singh, S., Roy, D., Sinha, K., Parveen, S., Sharma, G. \& Joshi, G. (2020). Impact of Covid- 13 and lockdown on mental health of children and adolescents: A narrative review with recommendations. Psychiatry Research, 293(220), 1-10.

Stark, A. M., White, A. E., Rotter, N. S., \& Basu, A. (2020). Shifting from survival to supporting resilience in children and families in the COVID-19 pandemic: Lessons for informing US mental health priorities. Psychological Trauma: Theory, Research, Practice, and Policy, 12(1), 133-135.

Tutar, H. \& Tuncay Erdem, A. (2020). Örnekleriyle bilimsel araştırma yöntemleri ve SPSS uygulamaları. Ankara: Seçkin Yayıncılık.

Wang, C., Pan, R., Wan, X., Tan, Y., Xu, L., Ho, C.S. \& Ho, R.C. (2020). Immediate psychological responses and associated factors during the initial stage of the 2019 coronavirus disease (COVID-19) epidemic among the general population in China. International. Journal of Environmental. Research Public Health 17 (5), 1729.

Whittle, S., Bray, K., Lin, S., \& Schwartz, O. (2020). Parenting and child and adolescent mental health during the COVID-19 pandemic. PsyArXiv, 1-42.

World Health Organization. (2004). The importance of caregiver-child interactions for the survival and healthy development of young children: http://repository.hsrc.ac.za/bitstream/handle/20.500.11910/8219/2393_Richter_TheImportanceChildgiverI nteraction.pdf?sequence $=1$ adresinden 17.12.2020 tarihinde erişilmiştir.

Yıldırım, A. \& Şimşek, H. (2018). Sosyal bilimlerde nitel araştırma yöntemleri. Ankara: Seçkin Yayıncllık. 
Yıldız, S. \& Bektaş, F. (2021). Covid-19 salgınının çocukların boş zaman etkinliklerinde yarattığı değişimin ebeveyn görüşleriyle incelenmesi. Gazi Beden Eğitimi ve Spor Bilimleri Dergisi, 26(1), 99-122.

Yılmaz Doğan, R. \& Aytekin, Ç. (2021). Ekolojik Sistem Kuramı çerçevesinden ebeveyn yabancılaşmasına genel bir bakış. Psikiyatride Güncel Yaklaşımlar, 13(3), 551-572.

Zhong, R. (2020). The coronavirus exposes education's digital divide. The New York Times, 15. 


\section{EXTENDED ABSTRACT}

\section{Introduction}

During the quarantine implemented due to the Covid-19 pandemic, students had limited educational opportunities, and online instruction led to certain social and academic consequences (Çakır Kardeş, 2020). Children had to participate in distance education activities and adapt to online education without support or certain orientation facilities provided by the education system (Çaykuş and Mutlu Çaykuş, 2020). Furthermore, due to their limited knowledge and maturity, children could have felt alienated or alone due to their limited understanding of the consequences of the pandemic (Singh et al., 2020). The Covid-19 pandemic forced individuals into obscurity and confusion in countries where it was prevalent, and it was determined that this phenomenon could lead to anxiety in children (Akoğlu and Karaaslan, 2020). The literature review revealed that several studies were conducted during the COVID-19 pandemic; however, the studies conducted on early childhood were generally about the psychological state of the children (Al-Balushi \& Essa, 2020; Dong et al, 2020; Griffith, 2020; Phelps and Sperry, 2020; Singh et al., 2020; Stark et al., 2020; Whittle et al., 2020). The review of the studies on education demonstrated that these were mainly on various teacher views (Alea et al., 2020), and the views of K-12 students (Fiş Erümit, 2020), and these studies were conducted with high school teachers and students (Niemi and Kousa, 2020). However, the review revealed no research on the views on the effects of the pandemic on children. Thus, the present study aimed to determine the changes introduced by the pandemic to the lives of children in early childhood and the effects of these developments on the children based on parental views. Accordingly, the following problem statements were determined:

Based on the views of the parents,

1) What are the changes introduced by the pandemic to the lives of preschool and school-age children?

2) What are the effects of these changes experienced by preschool and school-age children during the pandemic on the children?

\section{Method}

The present study, conducted to reveal the effects of the new normal on the early childhood period based on the views of the parents, was developed with the qualitative research approach. The study group included 20 parents with 4-7 years old children. Snowball sampling, a purposive sampling method, was employed in the assignment of participating parents. A semi-structured interview form was employed to collect the study data. Participants express their views more easily in semi-structured interviews. Furthermore, diverse questions could be included by the authors during the interviews to obtain in-depth information. The following steps were adopted in the present study in the analysis of the data: 1) After the data were collected, the audio recordings of each interview were stored in the computer environment, where the files were named as E.1, E.2, etc. The audio recordings were transcribed into interview forms without any alterations. After all the interview recordings were transcribed, the data that included five randomly selected interviews (25\% of the interview data) were verified by a researcher who was not involved in the transcription process. 2) After the transcription and verification, the data were coded and thematized by the authors independently. The authors then studied the codes and themes in collaboration and reached a consensus based on the discussion of their views. Once a consensus was reached, the codes and themes were organized, and the study findings were described and interpreted. Finally, two $(10 \%)$ of the participating parents were asked to clarify whether the described findings reflected their views. They reported that the findings completely reflected their views.

\section{Results}

The changed routines had certain effects on children's social-emotional, behavioral, language development, and motor skills. The most common emotions observed in children included anger, rebellion, unhappiness, withdrawal, sadness, fear of loss, aggression, and excessive mobility, stubbornness, crying and thumb-sucking behavior were observed in the children. The analysis of the speaking skills in language development revealed that they shouted at their cats, experienced speech difficulties, employed rude expressions in communication; however, it was mentioned that no decline was observed in motor skills, the 
in-classroom indifference of the children increased, and they experienced problems in following the instruction. The parents reported that there were changes in the perceptions of the children about the school such as longing for the school environment, reluctance towards the school activities, and they were unwilling towards the courses and course activities, anxious about academic failure. Due to online education, the study data revealed that the children could not connect with the teacher and/or missed their teachers and peers.

\section{Conclusion}

It was determined that with the introduction of the new normal, the children experienced certain changes in their lives and familial routines, and these changes mostly entailed restrictions in social activities. Consistent with the present study findings, Brazendale et al. (2017) reported that children exhibited lower physical activity levels, spent more on-screen time, and experienced sleep disorders, similar to weekends and summer holidays when they do not attend school. It was also determined that their diet had deteriorated, leading to putting on more weight and loss of cardiorespiratory fitness. Routine changes had certain effects on children's social-emotional, behavioral, language development, and motor skills. The most common emotional change was anger among the children. It was concluded that aggressive behavior was also observed. Abnormal behavior such as aggression, depression, panic, and paranoia was observed during the process, demonstrating that the pandemic did not only have physical but also psychosocial and emotional effects on the individuals (Karakaş, 2020).

Furthermore, certain changes were observed in the perceptions of the children about the school such as longing for school and unwillingness towards school activities. Friendship is essential for typical psychological development and well-being (WHO, 2004), and staying at home and away from the school environment, friends and teachers have negative effects on the psychological and physical health of the children (Brooks, Webster, Smith, Woodland, Wessely, Greenberg \& Rubin, 2020). 